\title{
Treatment with Haemodiafiltration Stabilises Vascular Stiffness (Measured by Aortic Pulse Wave Velocity) Compared to Haemodialysis
}

\author{
Evangelia Charitaki Daniel Belman Andrew Davenport \\ Centre for Nephrology, Royal Free Hospital, University College London Medical School, London, UK
}

\section{Key Words}

Hypertension · Haemodiafiltration · Haemodialysis · Pulse

wave velocity V Vascular calcification

\begin{abstract}
Background/Aims: Cerebrovascular diseases such as stroke are increased in dialysis patients, and haemodiafiltration has been reported to reduce cerebrovascular mortality compared to haemodialysis. We wished to determine whether haemodiafiltration improves arterial stiffness. Methods: We audited aortic pulse wave velocity (PWV) measurements 6 months apart in 3 cohorts of patients: 69 treated with haemodialysis, 78 who converted from haemodialysis to haemodiafiltration and 142 treated with haemodiafiltration. Results: Cohorts were well matched for age (means \pm SD: haemodialysis $64 \pm 15$ years vs. haemodialysis to haemodiafiltration $64 \pm 17$ years vs. haemodiafiltration $67 \pm 16$ years), sex (male 65 vs. 59 vs. $63 \%$ ), diabetes ( 45 vs. 56.4 vs. 44\%) and body mass index ( $26 \pm 6$ vs. $26 \pm 5$ vs. $26 \pm 5$ ), respectively. Systolic blood pressure did not differ over time (haemodialysis $143 \pm 25$ vs. $146 \pm 27 \mathrm{~mm} \mathrm{Hg}$, haemodialysis to haemodiafiltration $153 \pm 26$ vs. $154 \pm 25 \mathrm{~mm} \mathrm{Hg}$, haemodiafiltration $149 \pm 31$ vs. $148 \pm 30 \mathrm{~mm} \mathrm{Hg}$ ) or between groups. Aortic PWV significantly increased in the haemodialysis
\end{abstract}

group $(9.5 \pm 1.9$ vs. $10.2 \pm 2.2 \mathrm{~m} / \mathrm{s}, \mathrm{p}<0.01)$ and haemodialysis to haemodiafiltration group ( $9.4 \pm 1.9$ vs. $10.1 \pm 2.2$ $\mathrm{m} / \mathrm{s}, \mathrm{p}<0.01$ ), but did not change with haemodiafiltration $(9.9 \pm 2.1$ vs. $10.1 \pm 2.2 \mathrm{~m} / \mathrm{s})$. Conclusions: Aortic PWV, a measure of vascular stiffness, stabilised with haemodiafiltration. Our preliminary findings require further investigation to determine how haemodiafiltration may potentially improve vascular stiffness.

(c) 2014 S. Karger AG, Basel

\section{Introduction}

The prevalence of cardiovascular and cerebrovascular diseases is increased for patients with chronic kidney disease (CKD) stage 5 treated by dialysis (CKD5d) [1]. Compared to the general population, patients with CKD5d have increased rates of sudden cardiac death, heart failure and stroke [2]. Increased aortic stiffness with a correspondingly increased pulse pressure in the central arteries has repeatedly been reported as an independent predictor of cardio- and cerebrovascular events in both the general population [3] and also those with CKD5d [4].

Haemodiafiltration, which adds convective clearance to standard haemodialysis treatments, is becoming more

\begin{tabular}{ll}
\hline KARGER & $\begin{array}{l}\text { (c) 2014 S. Karger AG, Basel } \\
1660-2110 / 14 / 1282-0185 \$ 39.50 / 0 \quad \text { Karger } \\
\text { Open access }\end{array}$ \\
E-Mail karger@karger.com & $\begin{array}{l}\text { This is an Open Access article licensed under the terms of the } \\
\text { www.karger.com/nec }\end{array}$ \\
$\begin{array}{l}\text { Creative Commons Attribution-NonCommercial 3.0 Un- } \\
\text { ported license (CC BY-NC) (www.karger.com/OA-license), } \\
\text { applicable to the online version of the article only. Distribu- } \\
\text { tion permitted for non-commercial purposes only. }\end{array}$
\end{tabular}

Andrew Davenport, FRCP

Centre for Nephrology, Royal Free Hospital, University College London Medical School Rowland Hill Street

London NW3 2PF (UK)

E-Mail Andrewdavenport@nhs.net 
widely available [5]. Although haemodiafiltration does not lead to any discernible improvements in blood pressure control in CKD5d patients [6], it increases middlesized molecular weight solute clearances and improves phosphate control compared to standard haemodialysis [7]. More recently, a prospective trial of haemodiafiltration reported increased all-cause survival and in particular reduced cerebrovascular deaths compared to standard haemodialysis [8].

Pulse wave velocity (PWV), an assessment of aortic stiffness, can be reliably measured at the bedside $[9,10]$. We hypothesised that although haemodiafiltration does not improve blood pressure control, it may improve vascular reactivity with a reduction in vascular stiffness. To investigate this hypothesis we audited PWV measurements in CKD5d patients treated with haemodialysis, haemodiafiltration and those converted from haemodialysis to haemodiafiltration to determine whether haemodiafiltration resulted in any beneficial effect on PWV.

\section{Patients and Methods}

In adult CKD5d outpatients attending for their routine midweek dialysis treatments, aortic PWV measurements were performed before dialysis and then repeated after 6 months. All dialysis centres were temperature controlled. Aortic-brachial PWV was measured by a single observer using the Tensio Clinic Arteriograph (TensioMed Kft., Budapest, Hungary) oscillometric method, which has been validated against direct invasive measurements [9-11]. The distance between jugular notch and symphysis pubis was measured with a specially designed measuring device, and, after patients had rested, measurements were made in the recumbent position in the non-fistula arm.

All patients attending for dialysis were to be included; however, PWV measurements were not able to be recorded in patients with atrial fibrillation, other cardiac arrhythmias and fistulae in both arms, and in patients with no recordable upper arm blood pressure, and we excluded patients with severe aortic stenosis.

Augmentation indices (AXi) were calculated for the aorta and brachial arteries as the difference between the amplitudes of the late (backward) systolic wave (P2) and the early (forward) systolic wave $(\mathrm{P} 1)$ over the pulse pressure $(\mathrm{PP})$ multiplied with $100[\mathrm{AXi}=$ $(\mathrm{P} 2-\mathrm{P} 1) / \mathrm{PP} \cdot 100]$, and then adjusted for heart rate. The diastolic relaxation area (DRA), a measure of diastolic filling of the left coronary artery, was also adjusted for heart rate.

The Royal Free Hospital has no hospital-based dialysis facility and all CKD5d outpatients dialyse in satellite dialysis centres. Patient allocation to satellite centres was based on their post code (designed to minimise journey time to and from dialysis centres) and not on co-morbidity.

At the time of the blood pressure audit, the Royal Free Hospital was introducing haemodiafiltration as the standard of care for CKD5d patients. As such, some dialysis centres provided only haemodiafiltration, some haemodialysis and some converted from haemodialysis to haemodiafiltration during the 6-month audit period.
Table 1. Baseline demographics of the patients on high-flux haemodialysis (HD) and online post-dilution haemodiafiltration (HDF), and those who converted from HD to HDF

\begin{tabular}{llll}
\hline & HD & HD to HDF & HDF \\
\hline Patients, $\mathrm{n}$ & 69 & \multicolumn{1}{l}{78} & 142 \\
Age, years & $64.2 \pm 15.2$ & $64.1 \pm 16.5$ & $67.0 \pm 19.7$ \\
Males, \% & 65.2 & 59.0 & 62.6 \\
Diabetics, \% & 44.9 & 56.4 & 44.4 \\
Weight, kg & $72.5 \pm 16.6$ & $71.9 \pm 17.5$ & $70.5 \pm 16.3$ \\
Body mass index & $26.1 \pm 5.8$ & $25.8 \pm 5.2$ & $25.7 \pm 5.2$ \\
Dialysis vintage, & & & \\
$\quad$ months & $24(7-52)$ & $28.5(14-50)$ & $39(21-75)^{*}$ \\
Dialysis session, h & $3.92 \pm 0.36$ & $3.93 \pm 0.42$ & $3.99 \pm 0.37$ \\
Hypertension, \% & 72.2 & 66.7 & 85.9 \\
IHD, \% & 20.3 & 32.1 & 31.7 \\
PVD, \% & 14.5 & 14.1 & 23.9 \\
CVD, \% & 8.7 & 12.8 & 19.7 \\
Current smokers, \% & 14.5 & 13.7 & 3.5 \\
Ex-smokers, \% & 29.0 & 27.5 & 24.6 \\
ACEI/ARB, \% & 33.3 & 33.3 & 31.5 \\
CCB, \% & 24.6 & 15.4 & 22.5 \\
BB, \% & 42.0 & $12.8 *$ & $19.7^{*}$ \\
\hline
\end{tabular}

Results are expressed as means \pm SD or medians (interquartile ranges). $\mathrm{IHD}=$ Ischaemic heart disease (myocardial infarction, coronary artery stenting or bypass surgery); PVD = peripheral vascular disease (amputation, angioplasty or claudication); CVD = cerebrovascular disease (stroke or transient ischaemic attack); $\mathrm{ACEI}=$ angiotensin-converting enzyme inhibitors; $\mathrm{ARB}=$ angiotensin receptor blockers; $\mathrm{CCB}=$ calcium channel blockers; $\mathrm{BB}=$ $\beta$-blockers. ${ }^{*} \mathrm{p}<0.05$ by $\chi^{2}$ or ANOVA with post hoc correction vs. HD.

All patients were dialysed thrice weekly, targeted to achieve an online $\mathrm{Kt} / \mathrm{V}$ clearance of $\geq 1.4$ (Fresenius 4008/5008: Fresenius, Bad Homberg, Germany; Dialog+: B. Braun Medical Inc., Melsungen, Germany), using polysulfone dialysers (Nipro, Osaka, Japan) [12] and ultrapure quality dialysate, and anti-coagulated with tinzaparin (Leo Laboratories, Market Harborough, UK) [13]. Online post-dilutional haemodiafiltration was targeted to achieve $>16$ litres per convective therapy session [14]. Dialysate temperature was set at $35-35.5^{\circ} \mathrm{C}$, and dialysate sodium was regularly checked by flame photometry (Flame Photometer 943; Instrumentation Laboratory, Warrington, UK) with appropriate aqueous standards to ensure quality control [15]. Dialysate bicarbonate was set at 32 $\mathrm{mmol} / \mathrm{l}$ with $3 \mathrm{mmol} / \mathrm{l}$ of acetate.

A standard automated laboratory multichannel analyser was used for biochemical testing, with albumin measured using the bromocresol green method (Roche Integra; Roche Diagnostics, Lewes, UK). Subsets of patients had attended for transthoracic 2-dimensional echocardiograms (Philips IE33; Philips Medical Systems, Eindhoven, The Netherlands) or cardiac stress testing using adenosine triphosphate myocardial perfusion scintigraphy on a non-dialysis day [16]. 
Table 2. Baseline biochemical results of and bone mineral medications from the patients on high-flux haemodialysis (HD) and online post-dilution haemodiafiltration (HDF), and those who converted from HD to HDF

\begin{tabular}{lccc}
\hline & HD & HD to HDF & HDF \\
\hline Albumin, g/l & $40.2 \pm 4.2$ & $39.9 \pm 3.9$ & $39.4 \pm 3.8$ \\
Calcium, mmol/l & $2.31 \pm 0.16$ & $2.23 \pm 0.18$ & $2.27 \pm 0.17$ \\
Phosphate, mmol/l & $1.49 \pm 0.52$ & $1.42 \pm 0.46$ & $1.50 \pm 0.47$ \\
PTH, pmol/l & $23.1(13.2-47.4)$ & $27.1(13.8-57.8)$ & $27.5(15-53.4)$ \\
ALP, IU/l & $96(77-136)$ & $96(72-134)$ & $103(71-137)$ \\
Cholesterol, mmol/l & $3.87 \pm 0.98$ & $3.99 \pm 1.11$ & $4.02 \pm 1.13$ \\
HDL, mmol/l & $1.24 \pm 0.43$ & $1.31 \pm 0.49$ & $1.26 \pm 0.5$ \\
LDL, mmol/l & $1.96 \pm 0.83$ & $1.97 \pm 0.89$ & $2.1 \pm 0.93$ \\
Triglycerides, mmol/l & $1.2(0.8-1.9)$ & $1.3(0.9-2.3)$ & $1.3(0.9-1.8)$ \\
Statins, \% & 55.1 & 61.5 & 58.5 \\
Alfacalcidol, $\mu$ g/week & $2(0.75-4.63)$ & $1.75(0.75-6.0)$ & $2(0.75-4.5)$ \\
Calcium carbonate, \% & 50.7 & 53.8 & 53.5 \\
Sevelamer, \% & 10.1 & 9.0 & 21.8 \\
Lanthanum, \% & 11.6 & 12.8 & 18.2 \\
Cinacalcet, \% & 8.7 & 2.6 & 9.9 \\
\hline
\end{tabular}

Results are means \pm SD or medians (interquartile ranges). $\mathrm{PTH}=$ Parathyroid hormone; ALP = alkaline phosphatase. Statistical testing by $\chi^{2}$ or $t$ test with post hoc correction versus HD did not show any differences.

This retrospective audit fulfilled the UK Department of Health audit guidelines for clinical service development and was approved by the Royal Free Hospital Research and Development Office (International Clinical Trials Registry No. ISRCTN70556765).

\section{Statistical Analysis}

Statistical analysis was by Student's t test and Wilcoxon rank sum test for paired data, and $\chi^{2}$ test and one-way ANOVA or Kruskal-Wallis test with Tukey or Dunn's post hoc analysis correction (SPSS, version 20.0; SPSS Inc., Chicago, Ill., USA). Data are expressed as means $\pm \mathrm{SD}$, medians and interquartile ranges, or percentages. Statistical significance was taken at or below the $5 \%$ level.

\section{Results}

PWV was measured 6 months apart in 69 CKD5d HD patients, 142 patients treated with haemodiafiltration and 78 patients who had converted from haemodialysis to haemodiafiltration during the audit cycle. The groups were well matched in terms of demographics and past medical history (table 1), although there were fewer selfreported current smokers in the haemodiafiltration group, but similar numbers of ex-smokers. Similar numbers of patients were treated with anti-hypertensives, although proportionally more patients in the haemodialysis group were prescribed $\beta$-blockers.
Serum bone mineral biochemistry and lipid profiles were similar between the groups at baseline (table 2) and follow-up (online suppl. table 1; for all online suppl. material, see www.karger.com/doi/10.1159/000368242), and similar numbers were prescribed lipid-lowering drugs (statins), calcium-based phosphate binders and vitamin $\mathrm{D}$ analogues.

Patients receiving haemodiafiltration had a longer dialysis vintage, but median urine output was $<50 \mathrm{ml} /$ day in all groups. Dialysis session times did not differ, and there were no differences in dialysate composition between haemodialysis and haemodiafiltration groups (sodium $137.7 \pm 0.9$ vs. $137.5 \pm 1.2 \mathrm{mmol} / \mathrm{l}$, calcium $1.28 \pm$ 0.17 vs. $1.24 \pm 0.16 \mathrm{mmol} / \mathrm{l}$, potassium $2.0 \pm 0.5$ vs. 1.78 $\mathrm{mmol} / \mathrm{l}$, respectively). The median convective volume for the haemodiafiltration group was $18.6 \mathrm{l} / \mathrm{session}(16.8-$ 22.2). There were no differences in vascular access (haemodialysis: $66.7 \%$ arteriovenous fistula, $26.1 \%$ central venous catheters; haemodialysis to haemodiafiltration: $59 \%$ arteriovenous fistula, $39.7 \%$ central venous catheters; haemodiafiltration $71.8 \%$ arteriovenous fistula, $23.3 \%$ central venous catheters, the remainder dialysing with arteriovenous grafts).

There were no differences in the initial or repeat peripheral brachial pre-dialysis blood pressure or aortic PWV measurements between the 3 groups (table 3 ). 
Table 3. Blood pressure and aortic PWV measurements from the patients on high-flux haemodialysis (HD) and online post-dilution haemodiafiltration (HDF), and those who converted from HD to HDF taken during 2 audits (1 and 2) 6 months apart

\begin{tabular}{lccc}
\hline & HD & HD to HDF & HDF \\
\hline Heart rate 1, bpm & $72.8 \pm 13.3$ & $73.1 \pm 13.4$ & $73.4 \pm 14.2$ \\
Heart rate 2, bpm & $78.4 \pm 16.0$ & $76.6 \pm 14.3$ & $74.5 \pm 14.0$ \\
SBP-1, mm Hg & $142.6 \pm 24.9$ & $153.0 \pm 26.2$ & $148.7 \pm 31.2$ \\
SBP-2, mm Hg & $146.1 \pm 27.1$ & $154.0 \pm 24.6$ & $148.4 \pm 30.0$ \\
DBP-1, mm Hg & $76.5 \pm 12.8$ & $85.8 \pm 15.9$ & $78.9 \pm 15.8$ \\
DBP-2, mm Hg & $80.0 \pm 16.1$ & $83.6 \pm 17.1$ & $79.6 \pm 17.0$ \\
PP-1, mm Hg & $66.1 \pm 18.5$ & $67.3 \pm 17.1$ & $69.8 \pm 21.9$ \\
PP-2, mm Hg & $66.1 \pm 18.5$ & $70.5 \pm 17.3$ & $68.9 \pm 19.8$ \\
SBP Ao-1, mm Hg & $143.6 \pm 30$ & $154.9 \pm 30.9$ & $149.9 \pm 35.6$ \\
SBP Ao-2, mm Hg & $146.1 \pm 30.9$ & $155.4 \pm 28.2$ & $3.6(-32.2$ to 31.4) \\
BrAXi-1 & $1.9(-32.5$ to 28.4) & $5.3(-16.9$ to 28.4) & $4.0(-26.2$ to 23.3) \\
BrAXi-2 & $0.1(-27$ to 28.4) & $3.4(-16.3$ to 23.3) & $39.5 \pm 17.3$ \\
AoAXi-1 & $36.3 \pm 16.1$ & $38.5 \pm 14.4$ & $40.0 \pm 15.9$ \\
AoAXi-2 & $37.8 \pm 16.1$ & $41.2 \pm 14.4$ & \\
\hline
\end{tabular}

SBP = Systolic blood pressure; DBP = diastolic blood pressure; $\mathrm{PP}=$ pulse pressure; Ao = aorta. Augmentation indices $(\mathrm{AXi})$ of the brachial artery $(\mathrm{BrAXi})$ and aorta $(\mathrm{AoAXi})$ were all adjusted for heart rate. Results are means \pm SD or medians (interquartile ranges). No significant differences between the groups were found.

Table 4. Results of transthoracic echocardiography (ECHO) and isotope heart stress test from the patients on high-flux haemodialysis (HD) and online post-dilution haemodiafiltration (HDF), and those who converted from $\mathrm{HD}$ to HDF prior to the audit

\begin{tabular}{lccc}
\hline & HD & HD to HDF & HDF \\
\hline ECHO, n (\%) & $37(53.6)$ & $59(75.6)$ & $91(64.1)$ \\
Ejection fraction, \% & $60(55-60)$ & $60(45-60)$ & $60(50-60)$ \\
LVEDD, cm & $4.79 \pm 0.59$ & $4.61 \pm 0.74$ & $4.66 \pm 0.72$ \\
LV mass, g & $211(164-257)$ & $206(153-270)$ & $213(164-279)$ \\
LVMI, g/m & & $113(87-141)$ & $126(100-148)$ \\
Exercise test, n (\%) & $116(97-134)$ & $50(64.1)$ & $52(36.6)$ \\
Positive test, \% & $22(31.9)$ & 54 & 34.6 \\
\hline
\end{tabular}

Total number (\%) of patients tested in each group. LVEDD = Left ventricular end-diastolic diameter; LV = left ventricle; $L V M I=$ left ventricular mass index. Positive heart stress is defined as reversible changes in cardiac perfusion between stress and rest images. Results are means \pm SD or medians (interquartile ranges). No significant differences between the groups were found.

However, whereas the measured PWV increased over the 6-month period for both the haemodialysis and the haemodialysis changing to haemodiafiltration groups, there was no overall increase for the haemodiafiltration cohort (fig. 1). There were no differences in the brachial and aortic augmentation indices either between or within the groups, although there was a trend to an increase after 6 months of haemodialysis; the me- dian percentage increased from 9.1 and $5.3 \%$ for the brachial and aortic arteries, respectively, whereas the median percentage changes in augmentation indices after 6 months of haemodiafiltration were -1.4 and $-1.7 \%$, respectively. There were no differences between the groups for the DRA, but whereas the mean DRA increased in the haemodiafiltration cohorts, it fell in the haemodialysis group (fig. 2). 


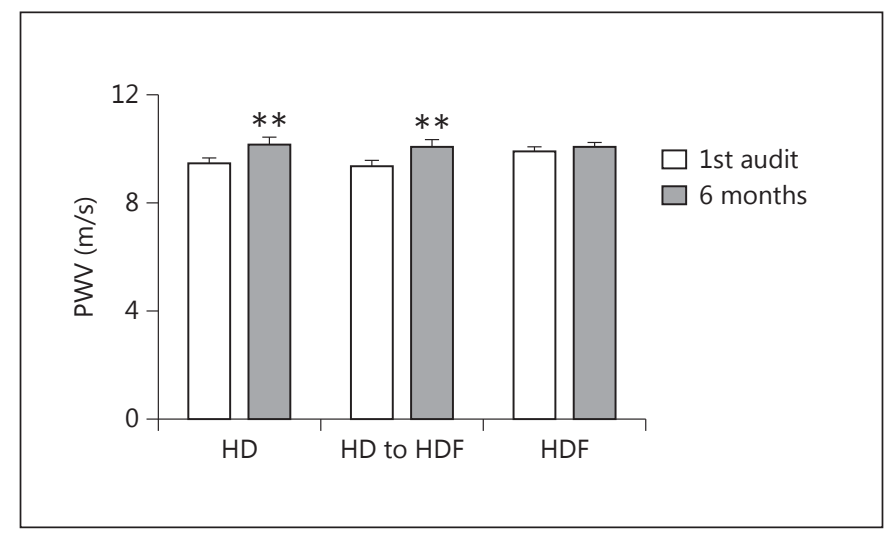

Fig. 1. Aortic PWV measured at two audits (taken 6 months apart) in 3 cohorts: those remaining on haemodialysis (HD), those converted from HD to haemodiafiltration (HDF) and those treated by HDF. Data are means \pm SEM. ${ }^{* *} \mathrm{p}<0.01$ vs. initial measurement.

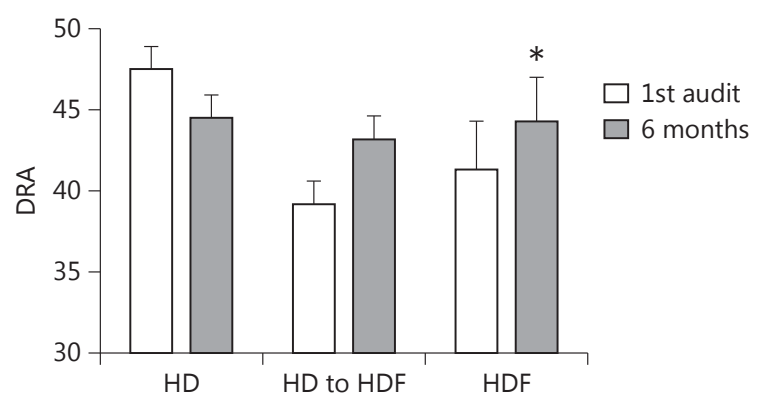

Fig. 2. DRA derived from PWV measurements at two audits (taken 6 months apart) in 3 cohorts: those remaining on haemodialysis (HD), those converted from HD to haemodiafiltration (HDF) and those treated with HDF. Data are adjusted for heart rate and expressed as means \pm SEM. ${ }^{*} \mathrm{p}<0.05$ vs. initial measurement.

To determine whether there was an effect of dialysis vintage, patients were divided into tertiles, and there was no difference in initial PWV (lowest to highest tertiles: $9.02 \pm 2.1$ vs. $9.56 \pm 3.2$ vs. $9.93 \pm 3.2 \mathrm{~m} / \mathrm{s}$, respectively) or PWV on follow-up $(9.46 \pm 2.7$ vs. $9.88 \pm 3.5$ vs. $9.87 \pm 3.5$ $\mathrm{m} / \mathrm{s}$, respectively). We then divided the haemodiafiltration group into tertiles by vintage, and again there was no difference between the tertiles (online suppl. table 2).

We then analysed the change in PWV according to the initial PWV by diving the whole cohort into tertiles (online suppl. table 3 ). Whereas PWV increased by 0.55 $(0.28-2.89) \mathrm{m} / \mathrm{s}$ for those starting in the lowest PWV ter- tile, it decreased in the highest tertile group [-1.48 $(-3.49$ to 0.32$) \mathrm{m} / \mathrm{s}, \mathrm{p}<0.001$ ]. Patients were then divided into tertiles for the different treatment modalities (online suppl. table 3). Although there was a difference in the change in PWV between the lowest and highest starting tertile for the haemodialysis group [0.55 (0.28-2.89) vs. -0.37 ( -2.93 to 2.17$), \mathrm{p}<0.05]$, this difference was much greater for the haemodiafiltration cohort [0.61 (0.16$2.08)$ vs. -1.88 ( -3.47 to -0.28$), \mathrm{p}<0.001]$.

Transthoracic echocardiograms were available for 187 patients (table 4). There were no significant differences in left ventricular hypertrophy or left ventricular ejection fraction. A minority of patients had undergone isotope heart stress testing, but a similar percentage of patients had demonstrable ischaemic heart disease.

\section{Discussion}

The majority of studies measuring PWV in dialysis patients have measured carotid-femoral or brachial-ankle PWV, so measuring a composite of aortic and conduit arteries [4], and thus overestimating aortic PWV [10]. More recently, aortic PWV has been reported to be an important independent risk factor for cardiovascular mortality in the general population [17]. Our 3 groups were relatively well matched for systolic hypertension, age, sex, body mass index and co-morbid conditions, including type 2 diabetes mellitus, which are recognised to affect PWV [3, 4]. Self-reported smoking habits were greater in the haemodialysis group, but there was no difference between the groups comparing non-smokers with ex- and current smokers.

Compared to previous studies measuring a composite of aortic and conduit PWV, our aortic pulse wave measurements were lower $[18,19]$. The device used in our study has been validated against direct invasive measurements $[9,11]$, and, by measuring the time required for the pulse wave to travel from the aortic root down to the aortic bifurcation and return coupled with the distance travelled, does not overestimate PWV [10, 18]. However, the device requires a minimum of three sinus beats and as such could not be used to measure PWV in patients with atrial fibrillation.

Our results showed an increase in aortic PWV in patients who remained on haemodialysis or were only recently transferred to haemodiafiltration, whereas there was no overall increase for those established on haemodiafiltration, and are supported by two earlier smaller single-centre studies: one reporting that patients dialysing with haemo- 
diafiltration had lower PWV measurements than those treated by conventional haemodialysis [20] and another noting increased PWV in haemodialysis patients, but with no increase with haemodiafiltration [21]. Although another study observed no differences in carotid-femoral PWV between haemodialysis and haemodiafiltration groups [22], this negative study of just over 100 patients employed multiple observers making a limited number of measurements in a younger dialysis population with fewer diabetics with no correction for heart rate. PWV is affected by peripheral blood pressure, vascular resistance and cardiac output, in keeping with these earlier studies.

Our haemodiafiltration patients had a longer dialysis vintage, and as such this may have affected PWV. Analysing the whole cohort, and then the effects of vintage for each of the three treatment modalities, we could not demonstrate a major effect of vintage on PWV. However, we did not have data on the time patients spent progressing through CKD stages 4 and 5 prior to the initiation of dialysis, and this may be an important factor as PWV has been reported to be increased in patients with CKD.

To ensure that changes in PWV are not simply determined by the initial PWV, with there being a maximum PWV above which further increases are limited due to a plateau effect, we analysed patients by their first PWV measurement. We did find that whereas PWV increased in those patients in the lowest starting tertile, there was a reduction for those in the highest tertile, and this difference was statistically greater for the haemodiafiltration cohort compared to the haemodialysis cohort.

Changes in vascular stiffness could reflect changes in vascular calcification, and although haemodiafiltration has been reported to improve serum phosphate control, this effect is generally modest [7]. Although there was a trend for the haemodiafiltration patients to be prescribed non-calcium-containing phosphate binders, this was not significant, and all groups were equally prescribed calcium-based phosphate binders. Whether haemodiafiltration has any beneficial effect on the regulators controlling soft tissue calcification remains to be determined. There could be subtle changes in the flux of sodium and calcium during haemodiafiltration compared to haemodialysis treatments due to higher volume convective therapy coupled with a cooling effect compared to the diffusional exchange with haemodialysis [23], which could potentially then affect vascular stiffness by altering medial calcium and sodium content.

To determine whether haemodiafiltration had any effect on arterial tone, we measured the augmentation index of the brachial artery and aorta. The lower the aug- mentation index then the greater the degree of arterial dilatation. As the augmentation index is affected by heart rate, all measurements were analysed after being standardised for heart rate. We did not find any significant changes in augmentation indices, although there was a trend to increase with haemodialysis, with no change for haemodiafiltration. This could potentially suggest improvement in endothelial function, and there are reports of reduced endothelial inflammation [24] and increased brachial flow-mediated dilatation and carotid artery distensibility with haemodiafiltration compared to haemodialysis [25].

An increase in DRA, a derived index reflecting diastolic filling, is associated with greater filling of the left coronary artery during diastole. There was a trend for the DRA to increase after 6 months of haemodiafiltration with no change in the haemodialysis cohort. Increasing DRA improves cardiac perfusion, and as such this may potentially reduce the risk of myocardial stunning with haemodiafiltration $[8,26]$. Haemodiafiltration additionally leads to greater thermal losses during treatment, and this may also help reduce the risk of intradialytic hypotension.

Our observational study suggested that although there were no differences in peripheral or central blood pressure after 6 months of haemodiafiltration, there were differences in PWV compared to haemodialysis. The greatest effect was observed in those patients starting with higher initial PWV. These changes were associated with improvement in cardiac diastolic perfusion and reduction in aortic and brachial augmentation indices. Taken together this would suggest a benefit for haemodiafiltration. However, our results have to be viewed in the context that we only measured changes over a 6-month period and that haemodiafiltration patients had a longer dialysis vintage, with fewer self-reported current smokers, and that PWV measurements were not possible in all patients. As such, further studies are required to confirm these preliminary findings and determine the underlying aetiology.

\section{Acknowledgement}

The study was supported by the Royal Free Hospital.

\section{Disclosure Statement}

The authors have no conflict of interest. 


\section{References}

1 Hou F, Jiang J, Chen J, Yu X, Zhou Q, Chen P, Mei C, Xiong F, Shi W, Zhou W, Liu X, Sun S, Xie D, Liu J, Zhang P, Yang X, Zhang Y, Zhang Y, Liang X, Zhang Z, Lin Q, Yu Y, Wu $S$, Xu X: China collaborative study on dialysis: a multi-centers cohort study on cardiovascular diseases in patients on maintenance dialysis. BMC Nephrol 2012;13:94.

2 van der Sande FM, Hermans MM, Leunissen KM, Kooman JP: Noncardiac consequences of hypertension in haemodialysis patients. Semin Dial 2004;17:304-306.

-3 Blacher J, Asmar R, Djane S, London GM, Safar ME: Aortic pulse wave velocity as a marker of cardiovascular risk in hypertensive patients. Hypertension 1999;33:1111-1117.

-4 Safar ME, Blacher J, Pannier B, Guérin AP, Marchais SJ, Guyonvarch PM, London GM: Central pulse pressure and mortality in end stage renal disease. Hypertension 2002;39: 735-738.

5 Tattersall JE, Ward RA; EUDIAL Group: Online haemodiafiltration: definition, dose quantification and safety revisited. Nephrol Dial Transplant 2013;28:542-550.

6 Pinney JH, Oates T, Davenport A: Haemodiafiltration does not reduce the frequency of intradialytic hypotensive episodes when compared to cooled high-flux haemodialysis. Nephron Clin Pract 2011;119:c138-c144.

7 Davenport A, Gardner C, Delaney M; Pan Thames Renal Audit Group: The effect of dialysis modality on phosphate control: haemodialysis compared to haemodiafiltration. The Pan Thames Renal Audit. Nephrol Dial Transplant 2010;25:897-901.

8 Maduell F, Moreso F, Pons M, Ramos R, Mora-Macià J, Carreras J, Soler J, Torres F, Campistol JM, Martinez-Castelao A; ESHOL Study Group: High-efficiency postdilution online haemodiafiltration reduces all-cause mortality in haemodialysis patients. J Am Soc Nephrol 2013;24:487-497.

\9 Horváth IG, Németh A, Lenkey Z, Alessandri N, Tufano F, Kis P, Gaszner B, Cziráki A: Invasive validation of a new oscillometric device (Arteriograph) for measuring augmentation index, central blood pressure and aortic pulse wave velocity. J Hypertens 2010;28:20682075.
10 Davies JI, Struthers AD: Pulse wave analysis and pulse wave velocity: a critical review of their strengths and weaknesses. J Hypertens 2003;21:463-472.

11 Sunbul M, Tigen K, Ozen G, Durmus E, Kivrak T, Cincin A, Kepez A, Atas H, Direskeneli H, Basaran Y: Evaluation of arterial stiffness and hemodynamics by oscillometric method in patients with systemic sclerosis. Wien Klin Wochenschr 2013;125:461-466.

12 Vernon K, Peasegood J, Riddell A, Davenport A: Dialyzers designed to increase internal filtration do not result in significantly increased platelet activation and thrombin generation. Nephron Clin Pract 2010;117:c403-c408.

13 Davenport A: Low-molecular-weight heparin as an alternative anticoagulant to unfractionated heparin for routine outpatient haemodialysis treatments. Nephrology (Carlton) 2009; 14:455-461.

14 Oates T, Cross J, Davenport A: Cost comparison of online haemodiafiltration with highflux haemodialysis. J Nephrol 2012;25:192197.

15 Davenport A: Negative dialysate to sodium gradient does not lead to intracellular volume expansion post haemodialysis. Int J Artif Organs 2010;33:700-705.

16 Moran N, Buscombe J, Davenport A: Predicting cardiac events using adenosine triphosphate myocardial perfusion scintigraphy in renal transplant candidates. J Nephrol Renal Transplant 2008;1:41-52.

17 Ben-Shlomo Y, Spears M, Boustred C, et al: Aortic pulse wave velocity improves cardiovascular event prediction: an individual participant meta-analysis of prospective observational data from 17,635 subjects. J Am Coll Cardiol 2014;63:636-646.

18 Utescu MS, Couture V, Mac-Way F, De Serres SA, Marquis K, Larivière R, Desmeules S, Lebel M, Boutouyrie P, Agharazii M: Determinants of progression of aortic stiffness in hemodialysis patients: a prospective longitudinal study. Hypertension 2013;62:154-160.

19 Boutouyrie P, Fliser D, Goldsmith D, Covic A, Wiecek A, Ortiz A, Martinez-Castelao A, Lindholm B, Massy ZA, Suleymanlar G, Sicari R, Gargani L, Parati G, Mallamaci F, Zoccali C, London GM: Assessment of arterial stiffness for clinical and epidemiological studies: methodological considerations for validation and entry into the European Renal and Cardiovascular Medicine registry. Nephrol Dial Transplant 2014;29:232-239.
20 Raikou VD, Tentolouris N, Kyriaki D, Evaggelatou $\mathrm{A}$, Tzanatou $\mathrm{H}$ : $\beta_{2}$-Microglobulin, pulse pressure and metabolic alterations in haemodialysis patients. Nephron Clin Pract 2011;117:c237-c245.

21 Ohtake T, Oka M, Ishioka K, Honda K, Mochida Y, Maesato K, Moriya H, Hidaka S, Kobayashi S: Cardiovascular protective effects of on-line hemodiafiltration: comparison with conventional hemodialysis. Ther Apher Dial 2012;16:181-188.

22 Mostovaya IM, Bots ML, van den Dorpel MA, Grooteman MP, Kamp O, Levesque R, Ter Wee PM, Nubé MJ, Blankestijn PJ: A randomized trial of hemodiafiltration and change in cardiovascular parameters. Clin J Am Soc Nephrol 2014;9:520-526.

23 Davenport A: Potential adverse effects of replacing high volume hemofiltration exchanges on electrolyte balance and acid-base status using the current commercially available replacement solutions in patients with acute renal failure. Int J Artif Organs 2008;31:3-5.

24 Heffernan KS, Kuvin JT, Sarnak MJ, Perrone RD, Miskulin DC, Rudym D, Chandra P, Karas RH, Menon V: Peripheral augmentation index and vascular inflammation in autosomal dominant polycystic kidney disease. Nephrol Dial Transplant 2011;26:2515-2521.

25 Bellien J, Fréguin-Bouilland C, Joannidès R, Hanoy M, Rémy-Jouet I, Monteil C, Iacob M, Martin L, Renet S, Vendeville C, Godin M, Thuillez C, Le Roy F: High-efficiency on-line haemodiafiltration improves conduit artery endothelial function compared with highflux haemodialysis in end-stage renal disease patients. Nephrol Dial Transplant 2014;29: 414-422.

26 McIntyre CW, Burton JO, Selby NM, Leccisotti L, Korsheed S, Baker CS, Camici PG: Haemodialysis-induced cardiac dysfunction is associated with an acute reduction in global and segmental myocardial blood flow. Clin J Am Soc Nephrol 2008;3:19-26.
Haemodiafiltration and Pulse Wave Velocity
Nephron Clin Pract 2014;128:185-191 